\title{
Creating Engaging Online Courses
}

\author{
doi:10.3991/ijoe.v5s2.1093 \\ S. M. Zvacek \\ University of Kansas, Kansas, USA
}

\begin{abstract}
The importance of engagement for learning, specifically related to online coursework, is discussed in this paper. The cognitive basis for engagement and instructional strategies for integrating it into coursework are described, as well as the challenges that instructors face in creating robust learning environments. The roles of teacher and learner must also evolve to accommodate these new models, with increased student responsibility and accountability. Finally, practical examples are given to demonstrate strategies for enhanced engagement in online coursework.
\end{abstract}

Index Terms-Education, Educational technology, Student experiments

\section{INTRODUCTION}

Faced with the prospect of developing, and then teaching, an online course, it's only natural to start by pondering, "What am I going to do?" The more important question, however, is, "What are my students going to do?" We know that humans learn by doing things - sometimes that "doing" is observable and easily measured, sometimes not -- but learning will not happen without the learner's involvement in the process. Based on this alone, online courses have an unprecedented opportunity to act as a catalyst for meaningful change in higher education by focusing on student engagement with resources such as online labs, remote-access content repositories, and collaborative interaction tools [1].

\section{IMPORTANCE OF ENGAGEMENT}

For the purposes of this paper and presentation, the term "engagement" will be defined as the act of doing something meaningful in a purposeful manner (i.e., not including involuntary or autonomic responses to stimuli, for example). Additionally, in this specific context, that activity will involve course content such as vocabulary words, concepts, hierarchies, theories, etc. Although humans are pre-wired to store and recall information, it takes purposeful engagement to build out the neural structures that are required for deep learning and critical thinking abilities.

Knowledge is represented in the brain within frameworks, or schemata, consisting of nodes (concepts, objects, facts, etc.) and the pathways among them. These pathways represent relationships or associations among the discrete pieces of information housed in each schema structure, and are potentially more important than the nodes themselves, not least because they enable us to retrieve specific facts, procedures, or whatever else happens to be in a node [2]. Schema structures are built or expanded upon when we manipulate information - compare it to something else, identify its component parts, categorize it, or otherwise do something with it. Constructivist theory suggests that by actively manipulating new content and purposefully integrating it with previously-learned concepts we improve our ability to transfer important knowledge and skills to new or unfamiliar situations - the ultimate goal of education.

Of the many challenges facing instructors, one of the most frustrating is the difficulty of demonstrating the relationship of theory to practice; that is, helping students to link the practical "how to do something" with the more theoretical "why it works" part of the course. Learning activities that involve both a practical element and a meaningful, engaging use of theory can help to bridge this gap. An example of this could be to have students conduct electronics experiments while studying transistors, and then to add the task of predicting how the output signal will vary when changes are introduced, such as strengthening the input signal. These student predictions should include a rationale to explain why a specific result will be obtained, to ensure that the predictor truly understands the theory behind the event. Another option is to require students to design an experiment that tests a given theory or concept, again exploring variations that strengthen understanding. The ideal outcome is that by tying theory to practice students will be able to make things work, but they also will understand why a similar device does not work (i.e., diagnose problems) when faced with such a situation beyond the classroom.

\section{IMPLICATIONS FOR TEACHING AND LEARNING}

When we design instruction - online or face-to-face that incorporates learner engagement, the familiar roles traditionally occupied by teachers and learners change significantly. Adopting the analogy of a theatrical event, students must give up their primary role of audience member and agree (however reluctantly) to act. Conversely, the teacher's performance role is reduced or eliminated altogether, and he/she takes on tasks resembling that of an acting coach or director.

The dissemination of information (as in the traditional lecture) can then be relegated to media well-suited to this task, such as textbooks, videos, audio presentations, graphics, or other content storage and distribution devices. The teacher's role now involves duties of greater importance than telling students things, and includes activities such as posing questions that challenge student assumptions, diagnosing and remedying misconceptions about course content, assessing learner progress, providing constructive feedback specific to individual needs, and motivating students to persist in their learning efforts [3], [4] and [5].

Teaching models have, for several years, focused almost exclusively on the teacher's role in the education process. For example, in the behaviorist view of learning, students are considered "input" to the system to be acted 
upon in some fashion, emerging from the experience exhibiting the desired behavior change. Student enters into a course, teacher does something [teaches], student leaves course after demonstrating mastery of desired skill. This model ignores some critical factors, one of the most important being that learning occurs within an individual at their discretion and cannot be imposed externally. Therefore, at least some level of engagement on the learner's part is required, balancing the equation with effort from both parties. With recent attention on student-centered course design (or the more provocatively labeled "brainbased learning") this emphasis on students as passive recipients of instruction to whom education is done is giving way to a perspective recognizing the need for cognitive engagement.

Integrating student engagement into online coursework is a way to provide reinforcement of important concepts, self-assessment, and motivation for learners. Student engagement, as a crucial element of online coursework, can form the basis for deep learning that transfers readily to new environments and this is, ultimately, the goal of education.

Such change in roles is not an easy process and the instructor implementing it for the first time will realize that this kind of teaching requires a great deal of hard work and creativity. He or she also may encounter resistance from students. This is not surprising - active learning is more work than simply memorizing a body of content but over time students will realize that not only do they learn more in this way, but that it can be an enjoyable experience at the same time. Another unfortunate effect of this role change is that school administrators (especially those with a more traditional perspective) may not understand it nor remember that the best evidence of quality teaching is found in what students do, not in what the teacher does.

\section{INTEGRATING ENGAGEMENT INTO ONLINE COURSEWORK}

The wonderful thing about teaching online is that there are a wide variety of tools and resources to choose from when developing a course. Selecting the appropriate instructional strategies does not occur, however, until after we've identified our specific outcomes - that is, determined what we hope our students will be able to do as a result of this course. Once those expectations are in place, the next question is, "What can students do to enable them to achieve those expectations?" The following guidelines may prove helpful to start:

- Require students to practice higher order thinking such as problem-solving or analyzing, and reduce the amount of simple cognitive tasks (memorization and recall, for example) as much as possible. For example, have each student find a website related to the course content and evaluate it for accuracy, bias, completeness, etc. This activity has the added advantage of emphasizing the relevance of course content to the world beyond the course boundaries.

- Require interaction between the learner and the teacher or tutor. In an online course the teacher/tutor must correspond with learners frequently to assess their progress, provide feedback, and offer motivation. For example, have students keep online journal, accessible only to themselves and the teacher, detail- ing their progress on a long-term project and reflecting on how they've learned from mistakes, focused their thinking, or made new connections among previously-learned ideas.

- Require interaction among learners. Today's professions employ individuals who can work as part of a team, communicate their ideas clearly, and solve problems collaboratively. Old models emphasizing competition among learners ignore this reality to our students' detriment. For example, create lab activities that students are expected to complete as part of an online group, including wiki-based reports to facilitate collaborative writing.

- Require frequent, meaningful demonstrations of progress. As students become accustomed to their new role as active learners, smooth the way by providing low-stakes opportunities to practice (and fail at) newly acquired skills, especially early in the course. Such assessments also provide useful feedback regarding course design and content resources (such as texts). For example, with content that is hierarchical in nature, require students to create an initial concept map that can then be expanded and elaborated on throughout the course. This assignment has the added advantage of alerting the teacher to student misconceptions before they interfere with further progress.

Integrating student engagement into online coursework is a way to provide reinforcement of important concepts, self-assessment, and motivation for learners. Student engagement, as a crucial element of online coursework, can form the basis for deep learning that transfers readily to new environments and this is, ultimately, the goal of education.

\section{ACKNOWLEDGMENT}

Dr. Zvacek would like to thank the IEEE Education Society and Distinguished Lecturer Program, for their generous support, as well as the IEEE Education Society Portugal Chapter.

\section{REFERENCES}

[1] M. Simonson, M. Albright, S. Smaldino, and S. Zvacek, Teaching and learning at a distance, 4th ed. Boston: Pearson; Allyn \& Bacon, 2009.

[2] D. A. Sousa, How the brain learns, 3rd ed. Thousand Oaks, CA: Corwin Press, 2006.

[3] Helen L. Chen, Lisa R. Lattuca, and Eric R. Hamilton, "Conceptualizing engagement: Contributions of faculty to student engagement in engineering," Journal of Engineering Education, v97(3); 339-353, 2008.

[4] NCREL (1997), "Indicators of Engaged Learning," Website, content retrieved 4/24/09 from: http://www.ncrtec.org/capacity/ profile/profeng.htm

[5] C. Robinson, H. Hullinger, "New benchmarks in higher education: Student engagement in online learning," Journal of Education for Business, v84 (2); 101-109, 2008.

\section{AUTHOR}

S. M. Zvacek is the Director of Instructional Development and Support at the University of Kansas, Lawrence, KS 66045 USA (e-mail: szvacek@ku.edu).

This article was modified from a presentation at the IRF'2009 conference in Porto, Portugal, July 2009. Submitted 08 October 2009. Published as resubmitted by the author on 20 October 2009. 